\title{
ÉXODO, GENEROSIDAD Y PERVIVENCIA DE ELVIRA ARQUIOLA***
}

\author{
Agustín Albarracín Teulón
}

Dpto. Historia de la Ciencia, CSIC.

Elvira Arquiola Llopis, La vejez a debate, Madrid, CSIC, 1995, 236pp.

Nos encontramos en la mítica Colina de los Chopos juanramoniana, en la Residencia de Estudiantes que nos abre generosamente sus puertas esta tarde. Y en este ambiente, ante mí un libro de Elvira Arquiola, La vejez a debate, editado hace pocos días por el Consejo Superior de Investigaciones Científicas, dentro de su Colección "Estudios sobre la Ciencia", con la colaboración de la Dirección General de Investigación Científica y Técnica del Ministerio de Educación y Ciencia y del Fondo de Investigación Sanitaria del Instituto de Salud Carlos III. Así de escueto y sencillo. Y sin embargo, bajo la fría realidad de su presencia, y en esta ocasión más que nunca, surge la imperiosa necesidad de hablar de este libro procurando que la subjetividad ceda paso a la objetividad, empresa para mí difícil. Difícil en cualquier circunstancia, porque la aparición de un libro, de cualquier libro, supone una cierta aventura exploratoria, una no siempre deseada desvelación del misterio último de su creador; a la postre, conlleva una cierta posibilidad de sugerencias, de indagación acerca de lo que con él nos quiere mostrar el autor, muy próxima a la aventura, repito, de intentar penetrar en su intimidad, sobrepasando a veces la propia intención de quien lo escribió. Pero tan azorante situación se incrementa en esta ocasión, es todavía más difícil ahora, por razones obvias: por tratarse de un libro de Elvira Arquiola como autora, y por tratarse de mi propia persona como presentador. Pero intentemos la empresa.

La preocupación de Elvira por el tema de la vejez, se inició de forma marginal en su Tesis Doctoral sobre la anatomía patológica en el siglo XVII, más concretamente, sobre la lesión anatómica en la obra de Wepfer, leída en Valencia el año 1974; se reiteró luego del mismo modo en su libro Arterioesclerosis, publicado con Luis Montiel en 1979. En ambos trabajos, la investigación de fuentes le hizo topar con las alteraciones histológicas encontradas por distintos autores en los ancianos, haciendo nacer quizá en ella un interés todavía indefinido por esta última ctapa de la vida. Pero tal interés se fue decantando y ampliando a partir de los años ochenta, y especialmente en nuestra última década, tanto con la dirección de Tesis Doctorales todavía inéditas como con Tesinas de Licenciatura - recuerdo ahora la que en 1986 dirigió a J. Pascual Santos, "Vejez y Geriatría en la obra de Gregorio Marañón"-. Y sobre todo con su actividad publicista en revistas como El Médico —-Hospitales geriátricos"—, Quirón —-La vejez en los Estados de Bienestar"—,

t:al: Palabras pronunciadas en la presentación del libro de Elvira Arquiola Llopis La vejez a debate, celebrada el 25 de febrero de 1996 en la Residencia de Estudiantes del CSIC. 


\section{ENSAYOS}

Dynamis - "La profilaxis de la vejez en la España Contemporánea"- y, ya postumamente, Asclepio - "La medicina española contemporánea en el debate sobre la vejez", cuyo original me había enviado pocos meses antes de su muerte- No es extraño, pues, que a lo largo de sus últimos años se dispusiese a escribir un libro en el que recogería su experiencia geriátrica, rica en lecturas y en investigación de fuentes. La impagable labor de Luis Montiel, autor también del bello prólogo con que se inicia el libro, "El último testimonio de una historiadora de la medicina", ha permitido compilar debidamente las páginas que Elvira dejó escritas y a las que, ya impreso, antecede un entrañable Proemio de Jose Luis Peset, impedido esta tarde, por fuerza mayor, de estar entre nosotros como por amistad y saber le correspondía y hubiese sido su deseo. Un proemio que críptica y cordialmente titula "Escribir para vivir, leer para esperar".

Un libro, pues, que recoge una labor de años y que en 236 páginas nos ofrece, como su título promete, un amplísimo debate sobre la vejez, un "análisis histórico de la situación sociosanitaria de la vejez en la actualidad", como explicita su subtítulo. Los criterios conceptuales, la historia de su conversión en cuestión social a partir del mundo clásico así como de su posible previsión, sus problemas médicos (fisiopatológicos, profilácticos y patológicos), la intervención en su estudio de los factores psicológicos y sociales, su necesaria especialización; y todo ello en el mundo moderno occidental, por supuesto, pero particularmente considerado en España, tema al que se consagra un capítulo entero. Concluye el libro presentando la actual conversión de la vejez de problema en reto, con unas últimas reflexiones acerca de lo personal, lo individual y lo colectivo en ese tránsito de lo que es problemático a lo que es desafío.

Este es el libro de Elvira Arquiola, La vejez a debate, aparecido en estos días. Pero yo no me puedo quedar en su superficie. Como su amigo durante más de veinte años, como su confidente a veces en nuestros despachos contiguos cuando todos, Instituto "Arnau de Vilanova" y Cátedra compartíamos nuestro trabajo en el Pabellón $5^{\circ}$ de la Facultad de Medicina, en la Ciudad Universitaria, y luego en largas conversaciones telefónicas o en visitas muy esporádicas - coloquialmente, yo para ella "el Jefe"; coloquialmente, ella para mí "Da Elvira"-, como testigo de tantos momentos de esperanza y de fracaso vitales, y rompiendo las fronteras de la pura objetividad a que al comienzo de mis palabras aludía, quiero entrar en la última entraña de La vejez a debate, tratando de esclarecer su significado.

Tres sentidos veo yo en el contenido del libro que nos ocupa: el testimonio de un personal éxodo interior, la magnanimidad, como respuesta a una incógnita, que translucen sus páginas y, por fin, la posibilitación con él de una pervivencia salvadora. Brevemente glosaré mi afirmación.

Elvira Arquiola tuvo el privilegio, el triste privilegio, de saber que no llegaría a la vejez. Sus últimos años fueron un peregrinar permanente, una lucha heroica hacia la meta que sabía imposible, un éxodo mosaico plagado a veces de escollos e incomprensiones que le acercaba a la etapa prometedora pero inaccesible. También ella, desde su monte Nebo particular, pudo decirse: veo la vejez pero no la alcanzaré. Y este libro es testimonio de sus afanes inconclusos. Pero entonces surge la incógnita: ¿por qué precisamente en estas circunstancias su decisión de consagrar sus últimos esfuerzos al tema éste de la vejez?

La cual pregunta nos acerca al segundo sentido de la obra. En principio podía pensarse que tal consagración se explicaría por, ella misma lo escribe, la proximidad de la vejez a la muerte. Se trataría de un periodo paralelo a su propia circunstancia biográfica, y escribiendo sobre ella se recreaba en su personal situación. Pero eso hubiera sido en ella puro autosadismo. Antes bien, creo que porque sabía lo inalcanzable de sus pretensiones, dedicando al tema los más difíciles años de su vida, noble y limpiamente, mostraba así su extraordinario temple, la magnanimidad de su ánimo. Frente a los testimonios casi unánimes de escritores de todos los tiempos: recordad a Lope, el genio 


\section{ENSAYOS}

literario del XVII: "Todo soy enfermedad/porque es la vejez su abismo"; recordad a Carles Churchill, el tan poco edificante satírico del XVIII: "Vejez, una segunda infancia por la naturaleza maldita.../débil, enfermiza, plena de dolores; en cada aliento/maldiciendo a la vida y, pese a todo, temerosa de la muerte" y tantos y tantos más. Pues bien; Elvira, pudiendo haberse apoyado en ellos y en su propio destino para soslayar un tema tabú para ella, sabiendo la realidad de todas estas circunstancias, y conociendo su limitación, tuvo sin embargo la generosidad de ofrecernos una visión ecuánime de lo negativo, apoyando con su saber lo positivo, lo quijotesco de la empresa. No, ella no llegaría a la tierra prometida pero generosa, casi deportivamente, nos legó su visión de la misma, dedicándose al tema sin un atisbo de acritud ni amargura.

Y por fin, acabo con ello, este libro nos posibilita la pervivencia de Elvira. Permitidme que en estos momentos exprese mis más intimos sentimientos: la angustia de esa imposibilidad terrena de una relación interpersonal con los que nos dejaron, el dolor de no haber llegado a hablar un día o de no haber proseguido una conversación interrumpida otro, interpuesta ya entre nosotros la barrera inexorable del "ya nunca jamás". Una barrera ésta que yo veo como una inmensa pared de cristal impenetrable, en principio totalmente transparente, dejando pasar desde el otro lado imágenes y vivencias bajo forma de recuerdos: no podemos hablar pero, al menos, podemos revivir el pasado y así, en cierto modo, revivir al ausente. Mas la vida prosigue con ritmo azacanado, las exigencias de cada instante obligan a poner la atención en otros asuntos y en otras personas y resulta que cuando en algún momento posterior volvemos a mirar hacia el cristal observamos que su transparencia es ya algo menor, que se va haciendo translucido y que hay recuerdos que se pierden y vivencias inaprehensibles. Hasta que un día esa pared que nos separa de la muerte se trueca en muro opaco. Al otro lado el que se fue, perdida ya toda posibilidad de rescatarlo en la memoria; a este lado de acá yo, viviendo todavía con resignación la impasible realidad de la imposible rememoración. Así una y otra vez, aumentando con los años este drama real de la lucha implacable entre el recuerdo de los que se nos fueron y aquella danza egoista de la vida que sigue. Lo cual parece conducirnos a una visión pesimista del equilibrio entre la vida y la muerte, a favor de aquélla.

Pero yo pienso que no, que ello no es cierto, que no es posible perder para siempre el contacto con la amiga que se fue. $Y$ recuerdo viejas lecturas de poetas y acudo a mi experiencia, y en todo ello encuentro el camino de una nueva esperanza, más acá de lo trascendente, en nuestra propia temporalidad. Junto a la evidencia de que la resignación y la cotidiancidad mitigan y ahogan tantas veces esè permanente revivir de los recuerdos y de las vivencias, esta otra evidencia de que la obra Ilevada a cabo por los que se fueron puede convertirse en puente de unión eterna. Cualquier obra: la pictórica, la sinfónica, la científica, la literaria sobre todo, porque nos permite, cn nuestra propia soledad de cada instante, abrir las hojas de un libro y, como escribió Quevedo, "Retirado en la paz de estos desiertos/con pocos doctos libros juntos/vivo en conversación con los difuntos/y cscucho con mis ojos a los muertos". Hablar y ecuchar con los propios ojos, al lado de acá del muro ya totalmente opacificado, en cualquier momento, en toda circunstancia. El libro, pues, ocasión de resurrección y herramienta de supervivencia. Y aquí encuentro el último sentido de La vejez a debate. Más allá de su destino, de sus avatares futuros, lo tomo entre mis manos no como lector crítico sino como amigo, como persona. Abro sus páginas, entreleo sus capítulos, me impongo de su contenido $y$, de repente, siento un estremecimiento extraño. Me acuerdo de don Miguel de Unamuno y voy musitando lentamente sus agónicos octosílabos: "Aquí os dejo mi almalibro,/hombre-mundo verdadero;/cuando vibres todo entero/soy yo, lector que en tí vibro".

Éxodo, magnanimidad y pervivencia de Elvira Arquiola. Eso significa para mí, nada más y nada menos, La vejez a debateque esta tarde estamos presentando. Gracias a todos. 